\title{
VIOLÊNCIA E INSEGURANÇA OBJETIVA EM PEQUENAS CIDADES: 0 TRÁFICO DE DROGAS EM FAIXA DE FRONTEIRA E O CONTEXTO NO NORTE PARANAENSE
}

Pedro Henrique Carnevalli Fernandes ${ }^{1}$ Angela Maria Endlich²

Resumo: "Era uma vez uma cidade pequena, tranquila e segura em que as portas e as janelas ficavam abertas", uma realidade que parece, cada vez mais, um resquício. Nesse sentido, o principal objetivo deste artigo é demonstrar a violência e a insegurança objetiva em pequenas cidades a partir da propagação, sem barreiras e fronteiras, do tráfico ilícito de drogas, que se articula à economia em redes e atinge essas localidades analogicamente à globalização. Os procedimentos metodológicos foram: levantamento bibliográfico, levantamentos de dados e elaboração da redação final. Para isso, o artigo transita pela faixa de fronteira, pelo tráfico ilícito de drogas e pela malha rodoviária enquanto rede de escoamento. Os resultados revelaram que o tráfico de drogas influencia na violência e na insegurança objetiva em pequenas cidades, sobretudo nas localizadas na faixa de fronteira.

Palavras-chave: Pequenas cidades. Tráfico de drogas. Violência.

\section{VIOLENCE AND OBJECTIVE INSECURITY IN SMALL TOWNS: THE DRUG TRAFFICKING IN THE BORDER BAND AND THE CONTEXT IN NORTH PARANAENSE}

Abstract: "Once upon a time there was a small, quiet and safe city in which the doors and windows were left open", a reality that seems, more and more, a remnant. In this sense, the main objective of this paper is to demonstrate violence and objective insecurity in small towns based on the spread, without barriers and borders, of illicit drug trafficking, which articulates with the network economy and reaches these locations analogously to globalization. The methodological procedures were bibliographic survey, data collection and preparation of the final essay. To this end, the paper travels across the border, through illicit drug trafficking and through the road network as a drainage network. The results revealed that drug trafficking influences violence and objective insecurity in small towns, especially those located on the border.

Keywords: Small town. Drug trafficking. Violence.

\section{VIOLENCIA E INSEGURIDAD OBJETIVA EM PEQUEÑAS CIUDADES: TRÁFICO DE DROGRAS EN BANDAS FRONTERIZAS $Y$ CONTEXTO EN EL NORTE PARANAENSE}

Resumen: "Había una vez una ciudad pequeña, tranquila y segura en la que las puertas y ventanas se dejaban abiertas", una realidad que parece, cada vez más, un

\footnotetext{
1 Universidade Estadual de Maringá (UEM), Universidade Estadual do Norte do Paraná (UENP). Cornélio Procópio (PR), Brasil. pedrofernandes@uenp.edu.br, https://orcid.org/0000-0001-7542-7912. 2 Universidade Estadual Paulista (Unesp), Departamento de Geografia, Programa de Pós-Graduação em Geografia da Universidade Estadual de Maringá (UEM). Maringá (PR), Brasil. amendlich@hotmail.com, https://orcid.org/0000-0001-5203-5828.
} 
remanente. En este sentido, el objetivo principal de este artículo es demostrar la violencia y la inseguridad objetiva en las ciudades pequeñas basadas en la propagación, sin barreras y fronteras, del tráfico ilícito de drogas, que está vinculado a la economía de la red y llega a estos lugares de forma análoga a la globalización. Los procedimientos metodológicos fueron: encuesta bibliográfica, recolección de dados y preparación del ensayo final. Con este fin, el artículo discurso a través de la frontera, a través del tráfico ilícito de drogas y a través de la red de carreteras como una red de drenaje. Los resultados revelaron que el narcotráfico influye en la violencia y la inseguridad objetiva en las ciudades pequeñas, especialmente en aquellas ubicadas en la frontera.

Palabras clave: Pequeña ciudad. Tráfico de drogas. Violencia.

\section{Introdução}

"Era uma vez...". Uma das expressões mais marcantes da infância brasileira representa a narração de acontecimentos (re)construídos por outras pessoas. Claramente, a expressão demonstra um resgate de fatos do passado, em uma reconstrução histórica que pode ser verídica ou fantasiosa, como um mito. Em diversas oportunidades, essa expressão transparece uma mudança, ou seja, um cenário que enfrenta nova perspectiva. Então, "era uma vez uma cidade pequena tranquila e segura em que as portas e janelas ficavam abertas..." tem a finalidade de desmitificar a pequena cidade tranquila e segura.

A compreensão da materialização da violência e da insegurança objetiva em pequenas cidades ocorre a partir de diferentes dimensões espaciais de análise, perpassando escalas geográficas que querem demonstrar que a situação parece não ser exclusividade de determinados recortes do espaço geográfico, mas se estende a outros e deve ser entendida em uma perspectiva mais geral.

A escolha do recorte espacial das pequenas cidades justifica-se por tratar-se de espaços que vivenciaram nos últimos anos transformações econômicas, sociais, políticas, culturais etc., significativas. Além disso, os estudos sobre as pequenas cidades configuram-se como uma das frentes mais recentes da Geografia Urbana e se deparam com um contexto nacional de dimensão continental, construído a partir de múltiplas características regionais e locais.

As áreas fronteiriças são espaços marcados e reconhecidos pela violência quase que crônica. É comum encontrar trabalhos acadêmicos, políticas públicas, programas sociais e reportagens de diferentes meios de comunicação abordando situações violentas nesses espaços. Apesar disso, as violências, especialmente as voltadas ao tráfico ilícito, esbarram nos limites das informações e na concentração, quase que total, de estudos de cidades maiores e fronteiriças. 
Como a maioria dos municípios que se encontram em uma área de fronteira é polarizado por uma pequena cidade, é preciso considerar e dissertar sobre essa realidade. A partir das fronteiras, esses crimes, especialmente os relacionados ao tráfico ilícito de drogas, escoam para os demais espaços. Diante disso, este artigo transita por um dos fatores explicativo para a existência da violência e da insegurança objetiva em pequenas cidades. É fundamental revelar que esse fator explicativo se soma a outros dois: (i) a difusão e o transbordamento da lógica metropolitana, tais como hábitos e costumes, especialmente pela mídia e internet; (ii) a perda de centralidade e o esvaziamento demográfico dos núcleos urbanos arrefeceram uma série de serviços, inclusive os de segurança pública (FERNANDES, 2017).

O principal objetivo deste artigo é demonstrar a violência e a insegurança objetiva em pequenas cidades a partir da propagação, sem barreiras e fronteiras, do tráfico ilícito de drogas, que se articula à economia em redes e atinge essas localidades analogicamente à globalização.

Os procedimentos metodológicos foram: (i) levantamento bibliográfico, leitura e fichamento de livros e capítulos de livros, teses e dissertações, artigos, crônicas e textos relacionados aos temas da pesquisa; (ii) levantamentos complementares para entender o fator explicativo da pesquisa, sobretudo nos 186 municípios que compõem o Norte do Estado do Paraná; (iii) sistematização das informações e dos dados coletados; e (iv) elaboração da redação final deste artigo. O Norte do Paraná é compreendido pelo agrupamento de três mesorregiões, Norte Pioneiro, Norte Central e Noroeste, que somam pouco mais de 65 mil km² ou 32,6\% do Estado; 3,26 milhões de habitantes ou $31,2 \%$ da população paranaense; e 186 municípios ou $46,6 \%$ do total estadual (IBGE, 2010).

O artigo está estruturado em três partes, além da introdução, das considerações finais e das referências: na primeira, debate-se a faixa de fronteira brasileira e o contexto do Norte paranaense; na segunda, transita-se pelo tráfico de drogas e o seu contexto no Norte do Paraná; por fim, a terceira parte destaca a malha rodoviária, responsável por escoa considerável parcela do tráfico de drogas, influenciando na violência e na insegurança objetiva. 


\section{Faixa de fronteira e o contexto paranaense}

A faixa de fronteira, definida por meio da Lei no 6.634, de 02/05/1979, regulamentada pelo Decreto no 85.064 , de 26/08/1980, compreende uma faixa interna de 150 quilômetros de largura, paralela aos 15.735 quilômetros de linha divisória terrestre do território nacional (BRASIL, 1979). Devido ao tamanho e à localização, o Brasil faz fronteira com dez países, sendo que a faixa de fronteira corresponde a $27 \%$ do território nacional e contempla 11 Estados (Acre, Amapá, Amazonas, Mato Grosso, Mato Grosso do Sul, Pará, Paraná, Rio Grande do Sul, Rondônia, Roraima e Santa Catarina), 588 municípios e dez milhões de habitantes (BRASIL, 2005). Essa faixa de fronteira foi dividida em três grandes delimitações, denominadas de arcos, e em 19 sub-regiões, que se fundamentam a partir do desenvolvimento regional e da identidade cultural (BRASIL, 2005). A Tabela 1 promove uma síntese das sub-regiões da faixa de fronteira apresentando a quantidade de municípios, de população total e a proporção de pequenas cidades em cada uma.

Tabela 1. Brasil. Municípios, população total e proporção de pequenas cidades, por subregiões de faixa de fronteira, 2010

\begin{tabular}{|c|c|c|c|}
\hline Sub-região (Estado) & Municípios & Pop. Total & $\begin{array}{l}\text { Pequenas } \\
\text { cidades }^{1}\end{array}$ \\
\hline $\begin{array}{l}\text { Oiapoque-Tumucumaque } \\
\text { (AM, AP, PA, RR) }\end{array}$ & 18 & 365.816 & $66,7 \%$ \\
\hline Campos do Rio Branco (RR) & 09 & 394.375 & $77,8 \%$ \\
\hline Parima-Alto Rio Negro (AM, RR) & 07 & 123.557 & $71,4 \%$ \\
\hline Alto Solimões (AM) & 08 & 201.277 & $50,0 \%$ \\
\hline Alto Juruá (AC, $A M)$ & 13 & 238.910 & $69,2 \%$ \\
\hline Vale do Acre-Alto Purus (AC, AM) & 16 & 614.040 & $62,5 \%$ \\
\hline Madeira-Mamoré (RO) & 05 & 537.777 & $20,0 \%$ \\
\hline Fronteira do Guaporé (RO) & 14 & 232.433 & $78,6 \%$ \\
\hline Chapada dos Parecis (MT, RO) & 14 & 293.832 & $78,6 \%$ \\
\hline Alto Paraguai (MT) & 18 & 206.695 & $61,1 \%$ \\
\hline Pantanal (MT, MS) & 10 & 372.657 & $40,0 \%$ \\
\hline Bodoquena (MS) & 07 & 105.254 & $71,4 \%$ \\
\hline Dourados (MS) & 16 & 434.556 & $62,5 \%$ \\
\hline Cone Sul Mato-grossense (MS) & 15 & 300.751 & $80,0 \%$ \\
\hline Portal do Paraná (PR) & 24 & 317.593 & $83,3 \%$ \\
\hline Vales Coloniais Sulinos/Sudoeste do Paraná (PR) & 115 & 2.047 .352 & $83,5 \%$ \\
\hline $\begin{array}{l}\text { Vales Coloniais Sulinos/ } \\
\text { Oeste de Santa Catarina (SC) }\end{array}$ & 82 & 828.368 & $91,5 \%$ \\
\hline $\begin{array}{l}\text { Vales Coloniais Sulinos/ Noroeste do Rio Grande } \\
\text { do Sul (RS) }\end{array}$ & 143 & 1.348 .363 & $90,9 \%$ \\
\hline $\begin{array}{l}\text { Fronteira da Metade Sul do Rio Grande do Sul } \\
\text { (RS) }\end{array}$ & 54 & 1.771 .703 & $55,5 \%$ \\
\hline Total & 588 & 10.735 .309 & $78,7 \%$ \\
\hline
\end{tabular}

Nota 1. Considerou-se municípios com população inferior a vinte mil habitantes

Fonte: Adaptado de Brasil (2005) e IBGE (2010) 
Os resultados mostram que a faixa de fronteira brasileira é composta majoritariamente por pequenas cidades. Por essa dimensão, a faixa de fronteira é um espaço peculiar, com sistemas sociopolíticos diferentes e com relações transfronteiriças muitas vezes não previstas pelo marco legal dos países (BRASIL, 2005). Sendo assim, esses sistemas e relações são de suma importância para a elaboração das políticas públicas, que devem ser pensadas para o contexto local de compartilhamento.

Isso se justifica, pois em alguns lugares da faixa de fronteira, há intensa circulação de pessoas e mercadorias, dada por movimentos pendulares de trabalhadores ou cidadãos em busca de atendimento por serviços oferecidos no outro lado da fronteira. Entretanto, os aparatos de controle dos Estados tendem a restringir esses movimentos, comprometendo a eficiência das relações transfronteiriças (BRASIL, 2005). Em suma, significa o controle sobressaindo as possibilidades de relações sociais.

Sendo assim, a faixa de fronteira brasileira configura-se como uma região "pouco desenvolvida economicamente, historicamente abandonada pelo Estado, marcada pela dificuldade de acesso a bens e serviços públicos, pela falta de coesão social, pela inobservância de cidadania e por problemas peculiares às regiões fronteiriças" (BRASIL, 2009, p. 6).

Machado (2010) elucida algumas críticas às estratégias nacionais de combate ao tráfico ilícito de drogas. Inicialmente, ela discorda do uso das Forças Armadas (FA) como forças policiais na repressão ao tráfico nas fronteiras internacionais, especialmente na Amazônia. Logo, "ampliar as atribuições das FA no sentido de interferência direta e contínua em atos de repressão ao tráfico de ilícitos no terreno é confundir as atribuições constitucionais e a hierarquia institucional de cada órgão do governo federal" (MACHADO, 2010, p. 100).

O Paraná é a segunda Unidade da Federação em número de municípios que pertencem à faixa de fronteira, atrás apenas do Rio Grande do Sul. O Estado possui 139 municípios nessa condição $(23,6 \%$ do total de municípios brasileiros na faixa de fronteira e a $34,8 \%$ do total de municípios do Paraná). A Figura 1 apresenta os municípios do Norte do Paraná que compõem a faixa de fronteira, em 2015. 
Figura 1. Norte do Paraná. Municípios da faixa de fronteira, 2015

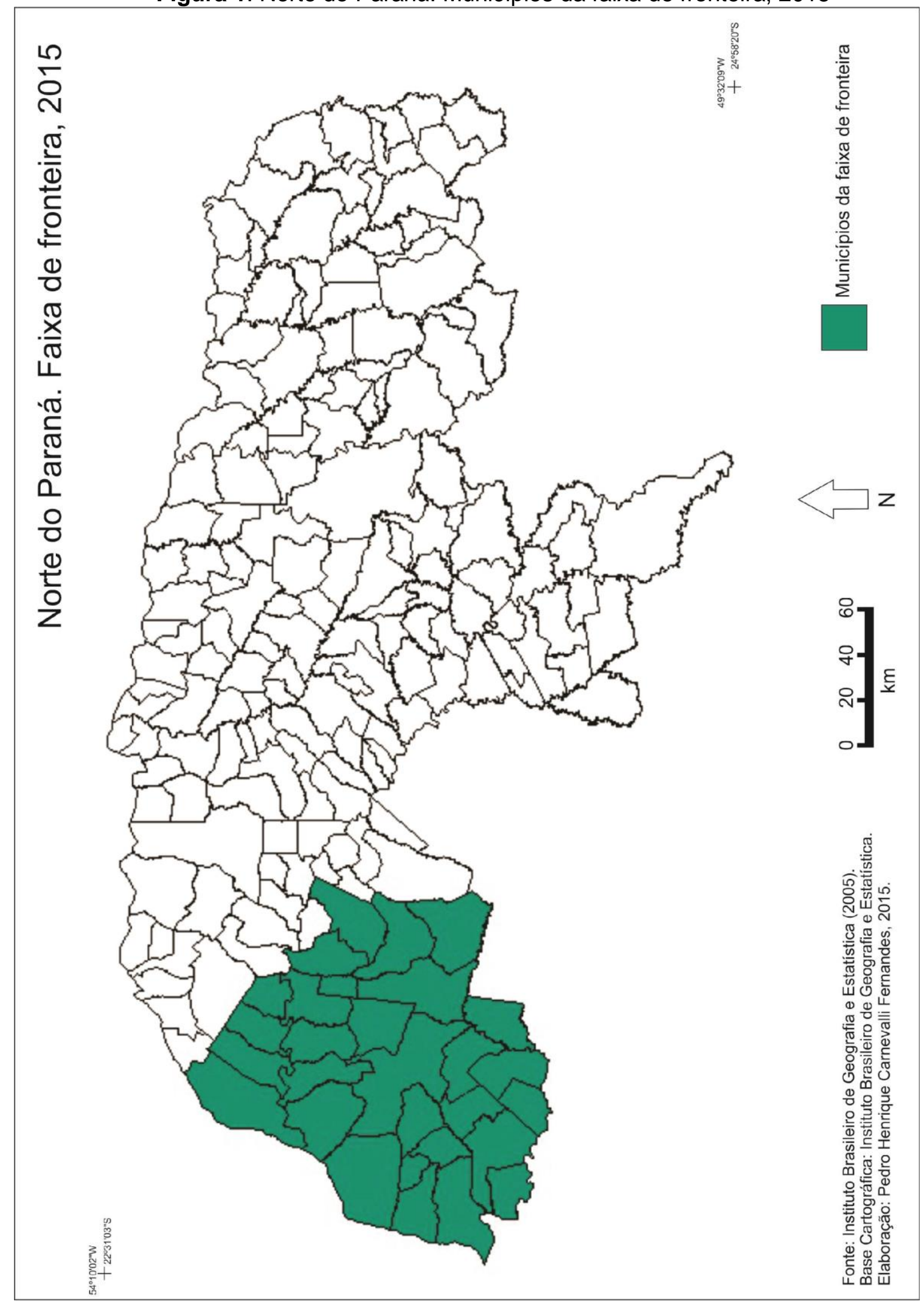

Fonte: Fernandes (2017)

Entre os municípios paranaenses na faixa de fronteira, 29 (ou 20,9\% deles) se localizam na região Norte do Paraná, o que representa 340 mil habitantes ou 10,4\% da população total da região. Com exceção de Umuarama, que concentra quase 
$30 \%$ de toda a população da faixa de fronteira da região, os demais municípios são polarizados por pequenas cidades. Entre eles, cinco municípios (18\%) possuem menos de cinco mil habitantes e 19 (68\%) têm, no máximo, dez mil habitantes. Apenas dois municípios, Altônia e Cruzeiro do Oeste, possuem mais de vinte mil habitantes (IBGE, 2010).

\section{O tráfico de drogas ilícitas nas fronteiras e o contexto no Norte do Paraná}

A ampliação da porosidade das fronteiras dos Estados Nacionais sobre a sustentação das benesses do comércio global (considerado legal), entendida como resultado das mudanças do capitalismo globalizado, sobretudo nas articulações em blocos econômicos, promoveu outra situação igualmente significante: a ampliação do comércio denominado ilegal. Nesse sentido, Dorfman (2009) destaca que a fronteira é um objeto cuja emergência liga-se aos processos de territorialização.

Enquanto continuum dentro de um processo de dominação e/ou apropriação, o território e a territorialização devem ser trabalhados na multiplicidade de suas manifestações - que é também e, sobretudo, multiplicidade de poderes, neles incorporados através dos múltiplos sujeitos envolvidos (HAESBAERT, 2007, p. 22).

Por isso, ampliaram-se as políticas de controle do território, potencialmente nas faixas de fronteira, e de relacionamentos em redes por meio do capitalismo e seus "paradigmas territoriais", no qual se funda, geograficamente:

Um mais típico da lógica estatal "tradicional", preocupada com o controle de fluxos pelo controle de áreas, quase sempre contínuas e de fronteiras claramente definidas; outro mais relacionado à lógica empresarial, também controladora de fluxos, porém prioritariamente através de sua "canalização" em dutos e nódulos de conexão (as redes), de alcance, em última instância, global (HAESBAERT, 2007, p. 29).

Diante de uma série de motivações para a violência e para a insegurança objetiva nas cidades fronteiriças e nas faixas de fronteiras, a que tem maior relevância, inclusive na política mundial de controle do território (e na produção de territorialidades), é o tráfico de drogas ilícitas e de produtos contrabandeados. Isso ocorre, segundo Machado (2011), porque, embora a economia das drogas ilícitas apresente implicações e efeitos diferenciados em cada país, o seu caráter, multinacional, é de acumulação de capital e está vinculado ao sistema financeiro internacional por meio da lavagem de dinheiro, escapando do controle de organismos nacionais e internacionais de segurança. 
Isso, segundo a autora, configura um novo referencial das relações interestatais, ou seja, tornou-se uma situação que extrapola as fronteiras da segurança interna. Esse processo vem corroendo os limites comumente conhecidos entre a segurança externa e a segurança interna já que, apesar de ter uma abordagem sistêmica, "a conexão com a florescente economia da segurança transformou (...) uma ferramenta conceitual em artifício político na medida em que torna secundária a diferença entre os estados nacionais em nome de uma problemática comum a todos" (MACHADO, 2011, p. 2).

As relações e interações que permeiam a linha tênue entre o legal e o ilegal, principalmente dos recursos oriundos de atividades de tráfico de drogas ilegais em negócios legais, ocorrem, segundo Machado (2011), a partir de alguns tipos de atividades econômicas legais que são atrativas para investimentos obtidos de forma ilegal: (i) os negócios de duplo propósito, legal e ilegal, como laboratórios farmacêuticos e farmácias, agronegócios, companhias de transporte e casas de câmbio; (ii) as atividades de prestígio e influência, como clubes esportivos, restaurantes e bares, escolas e faculdades e estações de televisão; e (iii) as redes de negócios, com destaque para a indústria turística, companhias imobiliárias e de investimentos, shoppings, empresas de construção e revendedoras de carros.

Então, o início do embate sobre o tráfico de drogas é chamado por Machado (2011) como "a caixa de pandora", já que remete à dupla face das drogas, medicamento e veneno, agravada pelo fenômeno contemporâneo da mercantilização da saúde ou invasão farmacêutica. Esse processo se inicia em meados do século XIX, "quando a revolução industrial ocidental transforma quimicamente as drogas de origem orgânica de uso local para serem consumidas de maneira massiva, distanciando-se do contexto e dos rituais originais milenares que haviam estimulado seu uso" (MACHADO, 2011, p. 3).

Para Rocha (2012), a droga ganhou novas significações na sociedade burguesa, transformando-se em droga-mercadoria, assumindo, por conseguinte, valor de troca. Nesse contexto, as drogas (lícitas ou ilícitas) "são mercantilizadas, produzidas e distribuídas a partir das relações estabelecidas no modo de produção capitalista. A produção em larga escala, modificada técnica e cientificamente, explora mais-valia do trabalho humano, tornando-se um lucrativo negócio" (ROCHA, 2012, p. 51). Assim, há uma imensa diferença entre o histórico da droga-produto, que possuía valor de uso, e o da droga-mercadoria, que tem, antes de tudo, valor de troca, sendo que a "droga-mercadoria só ganha status de mercadoria na 
sociabilidade burguesa por ser um objeto suscetível à mercantilização, que de uma maneira ou outra satisfaz necessidades de alguns sujeitos" (ROCHA, 2012, p. 51).

A partir da década de 1910, o Ocidente começou a regular o uso de narcóticos e a criminalizar o uso de algumas drogas. Entre as datas e eventos cronológicos apresentados por Machado (2011), os mais relevantes são a Convenção que restringiu a manufatura de narcóticos em 1925, a Convenção Única da ONU que proibiu o consumo e a produção de 108 substâncias orgânicas e sintéticas e foi assinada por 115 países em 1961; a Convenção de Viena, em 1971, contra o tráfico de narcóticos e psicotrópicos (ratificada por 76 países); a nova Convenção de Viena, em 1988, para reforçar a repressão internacional ao tráfico de drogas ilícitas; e, finalmente, a Conferência das Nações Unidas sobre Drogas, em Viena, em 2009, para revisar e criar políticas globais sobre as drogas.

Apesar disso, o grande marco da criminalização e da repressão contra as drogas ocorreu nos Estados Unidos da América, em 1973, com a política federal de "Guerra às Drogas (1973) como uma resposta à ameaça que representaria para a segurança nacional" (MACHADO, 2011, p. 4). Nesse cenário, a "guerra às drogas", segundo interpretação de Rocha (2012), acabou, mas prossegue como pretexto e instrumento legitimador para a perseguição e a própria violência contra os pobres, ou seja, a perspectiva ideológica é para o controle social e criminalização da pobreza e não para a proteção da sociedade.

A década de 2000 mudou a perspectiva sobre as drogas, passando de questão criminal nacional e transnacional para componente da segurança internacional, ou seja, para resolver os problemas internos (MACHADO, 2011). Diante disso, os espaços transversos de perspectiva concernentes à insegurança atingiram níveis globais de cooperação, com ampla inserção do tráfico, no que tangencia a segurança coletiva. Um ponto relevante que permite trazer o debate para o Brasil é justamente a rede internacional de tráfico de drogas ilícitas a partir da inserção brasileira nas "cartilhas dos princípios proibicionistas dos EUA, inclusive no que se refere à criminalização dos grupos considerados perigosos" (ROCHA, 2012, p. 75). Acerca do proibicionismo, Rocha (2012) considera que ele inaugurou o narcotráfico e todos os fenômenos que se ramificam dele, especialmente as ações de violência e a exploração intensa da mais-valia.

Como já se observou, a questão do tráfico ultrapassa as fronteiras nacionais e vincula-se, no mundo contemporâneo, à globalização, à internet e às novas tecnologias. Segundo Machado (2011), a lógica dessas redes se assemelha à 
logística da economia legal/formal de produtos, como plataformas e pontos de distribuição por atacado, aproveitamento da rede viária, portos e aeroportos e rotas fluviais. Além disso, as redes "constroem aparatos para a produção e venda das tais substâncias proibidas e outros fazem com que o mercado ilícito continue existindo, pois dependem dele, como clientes ou como provedores" (ROCHA, 2012, p. 92).

Sobre isso, a autora analisou os documentos da Comissão Parlamentar de Inquérito (CPI) do Narcotráfico que mostraram o envolvimento de agentes estatais do Paraná no crime organizado, com participação de superintendentes, delegados e investigadores. $\mathrm{Na}$ conclusão, os relatores consideram a questão do narcotráfico no Paraná profundamente séria, com envolvimento de maneira cristalizada de agentes da segurança pública, inclusive, na época, da alta cúpula de segurança do Estado (ROCHA, 2012). No Norte do Paraná, essa CPI revelou sólidas conexões com o narcotráfico paulista, sendo também mencionadas cidades pequenas da região de Londrina (ROCHA, 2012).

Misse (2006) entende que o denominado mercado das drogas e de outras mercadorias de bens ilícitos, da corrupção, da extorsão e das organizações criminosas que oferecem proteção, são reflexo do que Max Weber chamou de “capitalismo político". Em síntese,

Trata-se da emergência de formas sistemáticas e organizadas de empresas cujo lucro depende da produção e da troca de 'mercadorias políticas' (...). Tudo isso, a meu ver, participa de um processo através do qual o capitalismo moderno, economicamente racional, vem dando espaço (...) à re-emergência do capitalismo político (...) que é baseado na violência e na dominação pela força como mecanismo de acumulação do capital (MISSE, 2006, p. 23-24).

Nesse sentido, ao olhar para o Brasil, Misse (2006), não considera surpreendente viver uma realidade designada de violência na medida em que o País não concluiu o processo de modernização, não incorporou as massas no processo do capitalismo moderno, economicamente racional e orientado, não completou o assalariamento do trabalho e não conseguiu estender os direitos civis à maioria das pessoas. Assim, no Brasil, "internalizou-se a liberdade de transgredir 'justificadamente' (...), contra a universalidade da lei, sempre que eu encontrasse um bom motivo para isso" (MISSE, 2006, p. 24).

Para Arango (2014), a importância do tema da insegurança revela uma ambivalência na percepção da população jovem, que, sendo a principal vítima da crise urbana, carrega o estigma de ser culpada pela materialização da violência, como face visível do crime organizado. Isso ocorre, segundo a autora, porque a 
juventude, com a exclusão social, a marginalização por parte da sociedade e sem as oportunidades, é aliciada, sendo, por isso, vulnerável aos cartéis de drogas.

Colaborando com isso, Teixeira e Porto (1998, p. 53) consideram que a "falta de equipamentos de esporte e lazer, na maior parte das cidades e dos bairros", deixa as crianças e os adolescentes à mercê e, por conseguinte, tornam-se alvos do aumento da violência, especialmente para o consumo e tráfico de drogas ilícitas. Bezerra Júnior (2006) se espanta com a quantidade de adolescentes e jovens que são atraídos para o tráfico, apesar de saberem os resultados ruins dessa conduta. Para ele, a explicação desse risco vai além da questão material (e do dinheiro): "a admiração ou o medo que passam a despertar, o status que passam a ostentar" (BEZERRA JÚNIOR, 2006, p. 51), deixando de ser invisíveis socialmente quando, por meio da violência, impõem sua presença ao outro.

Por isso, para Rocha (2012, p. 23), “a atuação no tráfico de drogas pode ser considerada como um trabalho que acontece dentro da ilegalidade e das ligações tênues entre exploração, risco e satisfação". Dialeticamente, ganham visibilidade com o "poder" ou com as "políticas policialescas" que visam dar respostas à sociedade amedrontada pela violência e tornam-se os principais inimigos da sociedade (ROCHA, 2012). Nesse sentido, seu trabalho sobre o narcotráfico se desenvolveu pela ótica dos adolescentes explorados como "mulas" na rota internacional de drogas do Brasil - Paraguai, com destaque para o Paraná.

\footnotetext{
Tocar em temas que envolvem trabalhadores do tráfico é mexer com uma realidade que está lá, bem longe e aqui, bem perto. Está longe, nas comunidades precárias, pobres, onde o estado só entra para controlar por meio de políticas assistencialistas ou, pior que isso, políticas policialescas. Está perto, pois está aqui, agora, está na universidade, está nos bairros de classe média e alta, está nas baladas de sábado à noite, está nas rodas de esquinas, está no estresse dos trabalhadores de multinacionais ou dos "bóias frias" da colheita de cana (ROCHA, 2012, p. 22)
}

Logo, a violência do narcotráfico, que atinge o cotidiano dos jovens envolvidos no tráfico, é anterior a isso, ou seja, a violência subjetiva já é presente e constante no dia a dia deles, principalmente se forem pobres e negros, aos quais o estigma de criminoso historicamente - e injustamente - é vinculado a eles (ROCHA, 2012). Além disso, compõem, na maioria das vezes, estruturas mais simples de busca e entrega de drogas, não participando de redes internacionais. Essa atuação de "mula" compreende os trabalhos mais perigosos, já que são responsáveis pelo transporte de poucas quantidades de drogas, utilizando malas ou outros 
instrumentos e, em muitas vezes, até o próprio corpo, sendo, portanto, compostos de "mão de obra não qualificada", "volátil” e "substituível” (ROCHA, 2012).

No Paraná, segundo a autora, eles residem em um dos Estados mais ricos do Brasil e, ao mesmo tempo, às margens de qualquer garantia de direitos sociais, vivendo, então, em territórios, especialmente da fronteira, marcados pela ilegalidade e pelo narcotráfico, na qual o comércio e o trabalho no narcotráfico compõem uma relação complexa na divisão social e técnica do trabalho.

Dos 53 adolescentes apreendidos por transporte de drogas em rodovias do estado, no período de novembro 2009 a novembro de 2010, 57\% são do próprio estado do Paraná (...) e dentre estes, a maioria reside na (...) região de fronteira. Vemos nestes dados que há elementos que constroem uma territorialidade específica, ou seja, dentre as parcas atividades remuneradas oferecidas para os jovens da região, há a atuação no transporte de entorpecentes (ROCHA, 2012, p. 161).

Assim, "muitos jovens do estado estão prestando serviço ao tráfico de drogas, transportando entorpecentes dentro do próprio estado" (ROCHA, 2012, p. 237). Entre os residentes no Paraná, 31\% moravam na fronteira (Foz do Iguaçu ou Guaíra), $28 \%$ na faixa de fronteira paranaense e $41 \%$ em outras regiões do Estado (ROCHA, 2012). Portanto, quase 60\% deles estavam na fronteira ou a menos de 150 quilômetros dela, demonstrando a territorialidade desses lugares, assumindo uma condição de novos territórios a partir dela. Do universo de adolescentes apreendidos por tráfico de drogas, Rocha (2012) percebeu que 49\% retiraram a droga na própria região onde moravam e $51 \%$ saíram de suas cidades e foram buscá-las na fronteira (87\%) ou na faixa de fronteira (9\%).

O Governo do Estado do Paraná começou a divulgar, a partir de 2014, relatórios semestrais sobre a apreensão de diferentes tipologias de drogas ilícitas no Estado: maconha, cocaína e crack, por quilograma, e escstasy e LSD, por unidade (PARANÁ, 2015). Diante dos dados disponíveis até setembro de 2014, foram elaboradas duas taxas de apreensão de drogas para os municípios do Norte do Estado do Paraná: a taxa de apreensão de maconha, cocaína e crack, por quilograma, proporcional à população absoluta de cada município, por grupo de cem mil pessoas, e a taxa de apreensão de escstasy e LSD, por unidade, proporcional à população absoluta de cada município, por grupo de cem mil pessoas.

Os resultados da primeira taxa foram espacializados na Figura 2, que apresenta os municípios do Norte do Estado do Paraná por taxa de apreensão de drogas, em 2014. Os resultados da segunda taxa foram desconsiderados, já que 
apenas sete municípios, nenhum polarizado por pequena cidade, registraram apreensões de escstasy e/ou LSD.

No Norte do Paraná, em apenas 34 municípios (18,3\%) não houve apreensão de drogas em 2014, sendo todos eles com menos de dez mil habitantes. Com exceção de Iguaraçu, 18 municípios (9,7\%) apresentaram taxa de apreensão superior a uma tonelada de drogas, por cem mil habitantes, em 2014, sendo cinco deles na divisa com o Estado de São Paulo e sete na faixa de fronteira paranaense. A faixa de fronteira se destaca nesse cenário regional por possuir 12 dos 39 municípios com maiores taxas de apreensão de drogas, ou seja, quase um terço. Os resultados mostram ainda mais essa relevância da faixa de fronteira, já que abarca 11 ou $78,6 \%$ dos 14 municípios com taxas superiores a 350,1 quilogramas por cem mil habitantes, em 2014.

A partir da base do Narcodenúncia (PARANÁ, 2016), os dados absolutos de presos(as) por tráfico de drogas, entre 2003 e 2015, dos municípios do Norte do Estado do Paraná foram transformados em taxas por mil habitantes, a partir da população total dos municípios no último censo do IBGE (2010). Os resultados do cálculo foram espacializados na Figura 3, que apresenta a taxa de presos(as) por tráfico de drogas, entre 2003 e 2015, no Norte do Paraná.

Apenas 25 municípios (13,4\% do total) da região não tiveram nenhuma prisão por tráfico de drogas entre 2003 e 2015, sendo que 72\% deles possuíam, no máximo, cinco mil habitantes e todos eram polarizados por pequenas cidades. No oposto dos dados, 29 municípios (15,6\%) apareceram com taxa de presos(as), em grupo de mil, entre 2003 e 2015, superior a cinco, dos quais 51,7\% eram polarizados por pequenas cidades. Na faixa de fronteira, apenas três municípios $(10,3 \%$ da faixa) não apresentaram nenhuma prisão por tráfico de drogas, entre 2003 e 2015: Alto Paraíso, Brasilândia do Sul e Esperança Nova. No oposto, 12 municípios (41,4\% da faixa) passaram de cinco na taxa em grupo de mil pessoas no período, sendo 11 deles polarizados por pequenas cidades. Iporã, com 8,41 de taxa, e Cruzeiro do Oeste, com 7,10, apareceram com os maiores valores. 
Figura 2. Norte do Paraná. Taxa de drogas apreendidas, 2014

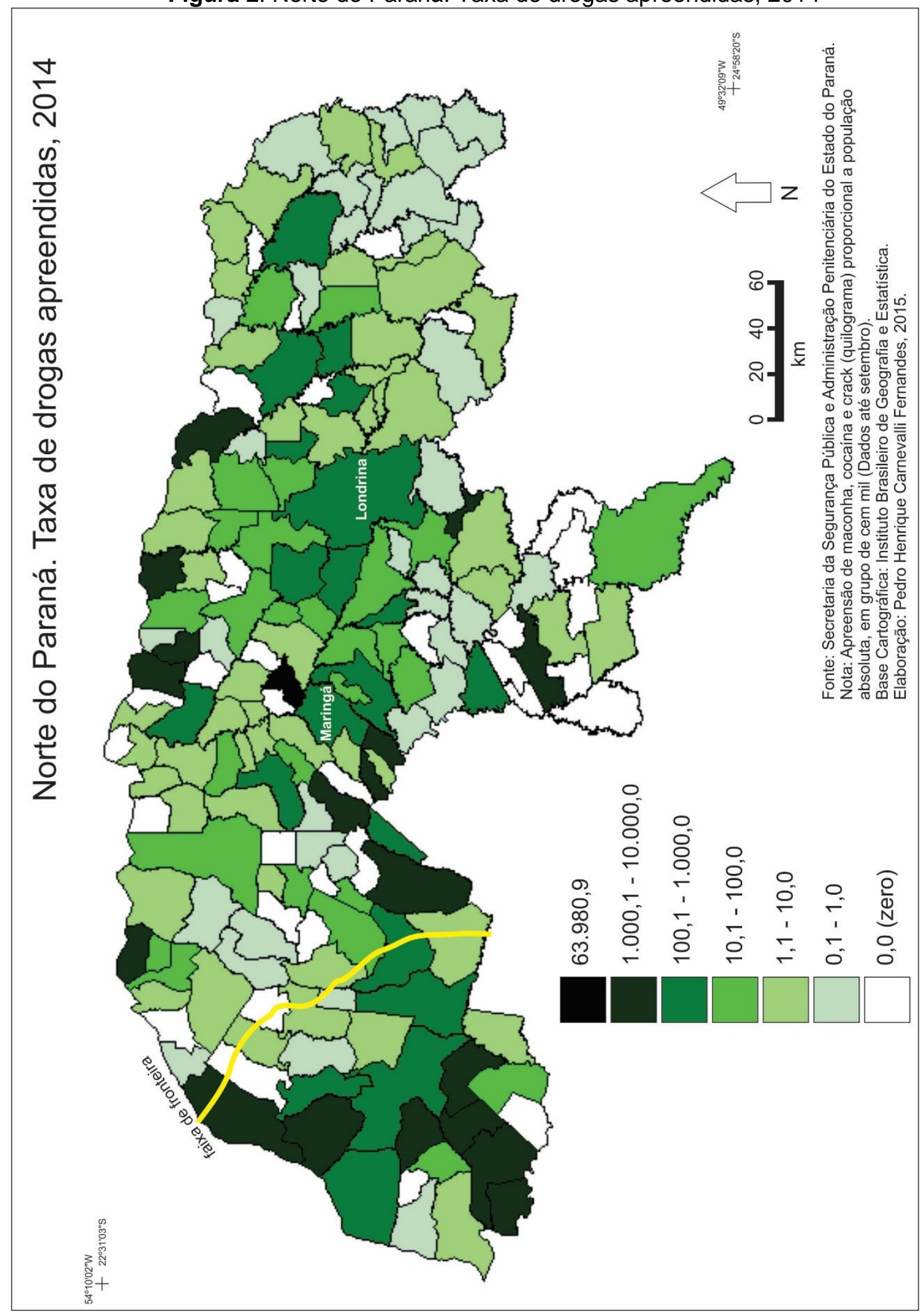

Fonte: Fernandes (2017). 
Figura 3. Norte do Paraná. Taxa de presos(as) por tráfico de drogas, 2003-2015

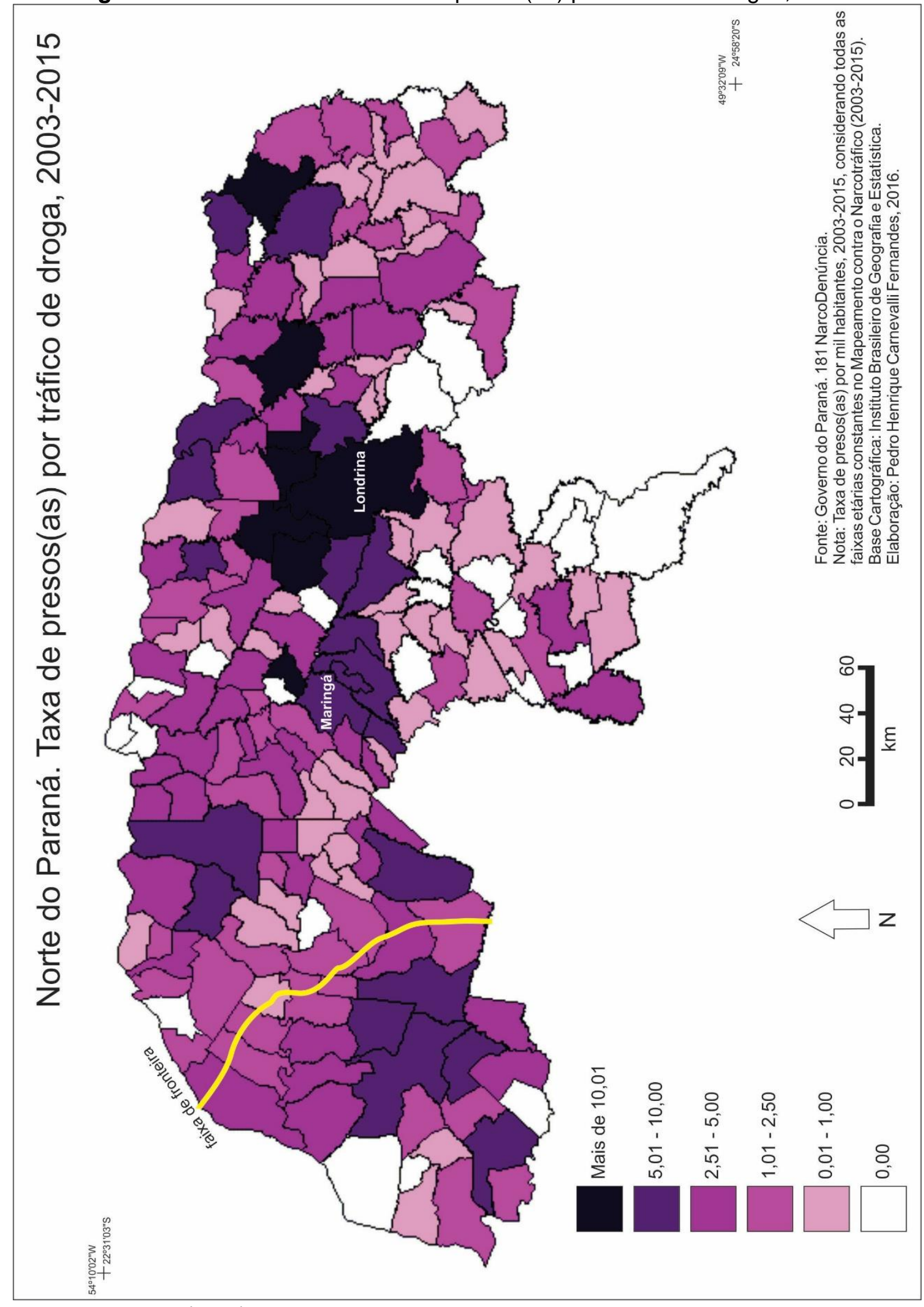

Fonte: Fernandes (2017) 


\section{A rede de escoamento do tráfico de drogas: a malha rodoviária e os serviços públicos de polícia}

O tráfico de drogas encontra (e utiliza) diversas redes geográficas para a sua materialização. Uma das mais utilizadas é a rede rodoviária. Por isso, esta seção do artigo transita pela malha rodoviária do Norte do Paraná, pelo viés de vias que articulam e escoam o tráfico de drogas, e pelos serviços públicos de polícia (Polícia Rodoviária Federal, Polícia Rodoviária Estadual do Paraná e Polícia Militar de Fronteira) na região, de modo a demonstrar uma ausência e/ou insuficiência dos serviços.

No Paraná, o órgão responsável pelas rodovias estaduais é o Departamento de Estradas e Rodagens (DER-PR), e pelas rodovias federais, o Departamento Nacional de Infraestrutura e Transporte (Dnit). A Figura 4 apresenta a malha rodoviária da faixa de fronteira no Norte do Paraná, em 2015, que ajuda a entender os fluxos da fronteira. Quatro rodovias se destacam, duas no sentido Leste - Oeste (PR-323/BR-272 e PR-082/PR492) e duas no sentido Norte - Sul (PR-486 e PR576/477).

A PR-323 vai de Sertaneja, na divisa do Paraná com São Paulo, até Iporã, no trevo com a PR-490, e, depois do trevo, ela torna-se BR-272 até Guaíra, na divisa brasileira com a paraguaia. A BR-272 foi projetada como uma rodovia de ligação de São Paulo (SP) com Guaíra (PR) e, consequentemente, com o Paraguai, mas se materializou em poucos trechos. Logo, é uma rodovia que liga Londrina e Maringá ao Paraguai, sendo reconhecida como uma das rotas mais usadas para o crime, especialmente de tráfico de drogas e de produtos contrabandeados.

A PR-082 tem um longo trajeto entre Jardim Alegre e o Distrito de Porto Camargo, município de Icaraíma, na divisão com o Mato Grosso do Sul. Em Rondon, há uma ramificação até Paranavaí, com denominação de PR-492, e até Cianorte, um entroncamento com a PR-323. A PR-486 vai do entroncamento da PR323 no povoado de Cedro, município de Perobal, até a região Oeste do Paraná, e a PR-576 sai de Porto Rico, nas barrancas do rio Paraná, e segue, no sentido Sul, até Tapira, quando se torna PR-477 até Cruzeiro do Oeste e, depois, se articula com a PR-180, sendo a principal ligação da região de Loanda com Toledo e Cascavel. 
Figura 4. Norte do Paraná. Malha rodoviária, 2015

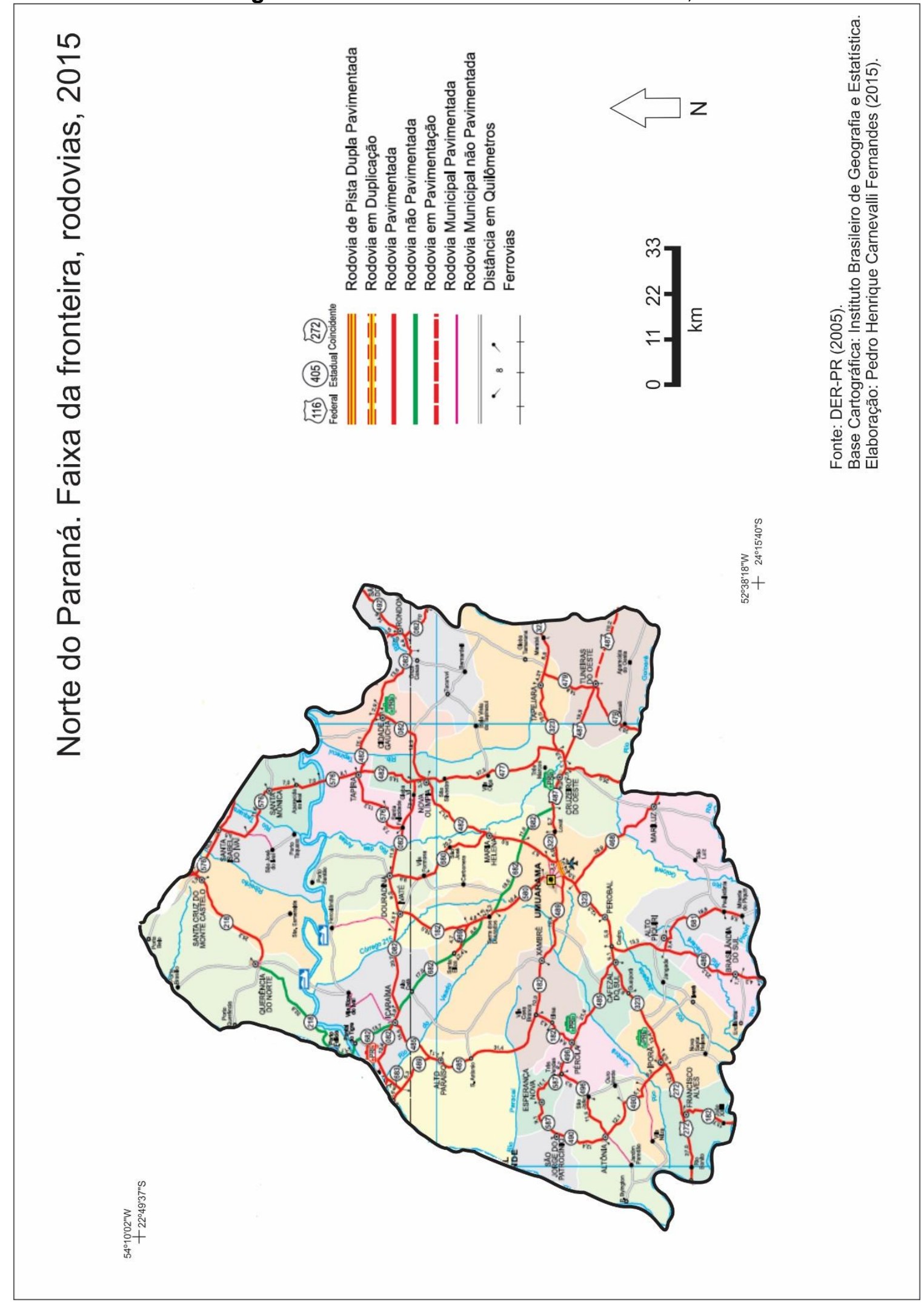

Fonte: Fernandes (2017)

As estradas se associam à segurança pública, especialmente em cidades pequenas, a partir de três situações: o acesso aos serviços de segurança; por se converterem em rotas de tráfico ilícito, especialmente de drogas e de produtos 
contrabandeados, da Bolívia e do Paraguai; e por serem espaços favoráveis para assaltos a ônibus de turistas e rotas de fuga para quadrilhas ou assaltantes que roubam comércio, bancos e caixas eletrônicos no urbano. Nesse sentido, o Quadro 1 apresenta alguns exemplos de crimes vinculados ao uso das rodovias no Norte do Estado do Paraná, entre 2010 e 2016, sobretudo os ocorridos em pequenas cidades.

Quadro 1. Norte do Paraná. Reportagens sobre crimes praticados em rodovias, 2010-2016

\begin{tabular}{|l|l|}
\hline Data & Reportagem \\
\hline $08 / 12 / 2010$ & $\begin{array}{l}\text { A "Rota Caipira do tráfico": articulação de policias intensificam } \\
\text { fiscalização na PR-160 (Porto Charles Nauffall), em Sertaneja (PCPR, } \\
2010)\end{array}$ \\
\hline $22 / 03 / 2013$ & $\begin{array}{l}\text { Estradas no Paraná têm um roubo de carga a cada dois dias (ROCHA, } \\
\text { 2013) }\end{array}$ \\
\hline $25 / 11 / 2014$ & $\begin{array}{l}\text { Paraná é o 3o em pontos de exploração sexual infantil em trechos de } \\
\text { rodovias federais (RIBEIRO, 2014) }\end{array}$ \\
\hline $04 / 08 / 2015$ & $\begin{array}{l}\text { Com apreensões diárias, PR-323, em lporã, é uma das rotas mais } \\
\text { usadas pelo crime (PORTAL DA CIDADE, 2015) }\end{array}$ \\
\hline $04 / 11 / 2015$ & $\begin{array}{l}\text { Falta de policiais deixa rodovias estaduais à mercê dos marginais } \\
\text { (BELO, 2015) }\end{array}$ \\
\hline $23 / 11 / 2015$ & $\begin{array}{l}\text { Polícia Rodoviária Federal acha carreta cheia de maconha e faz maior } \\
\text { apreensão de 2015 no país: 20 toneladas em Icaraíma (PORTAL G1/PR, } \\
\text { 2015) }\end{array}$ \\
\hline $19 / 01 / 2016$ & $\begin{array}{l}\text { Quadrilha faz reféns antes e depois de assalto a banco em Curiúva. } \\
\text { Bandidos interditam a PR-160 e fugiram (MAROS, 2016) }\end{array}$ \\
\hline
\end{tabular}

Fontes: PCPR (2010), Rocha (2013), Ribeiro (2014), Belo (2015), Portal da Cidade (2015), Portal G1/PR (2015) e Maros (2016)

Em 2010, uma operação policial intensificou a fiscalização na PR-160, no Porto Charles Nauffall, em Sertaneja, por considerar a rodovia como uma "rota caipira do tráfico" (PCPR, 2010). Outra rodovia que se destaca pelo tráfico de drogas é a PR-323, próxima a Iporã (PORTAL DA CIDADE, 2015). Além disso, a falta de policiais nas rodovias do Paraná (BELO, 2015) contribui com a violência, como em 2013, quando as estradas registravam uma média de um roubo de carga a cada dois dias (ROCHA, 2013), ou, em 2014, quando o Paraná assumiu o terceiro lugar em exploração sexual infantil nos trechos das rodovias federais (RIBEIRO, 2014).

Em 2016, uma rodovia do Norte do Estado foi cenário de uma ação e fuga com muita tensão e repercussão nacional, inclusive com gravação de um vídeo realizada por moradores da cidade. Na ação, uma quadrilha fez reféns ao assaltar um banco na pequena cidade de Curiúva e, depois, fugiu com eles, sendo que um refém foi amarrado sobre a parte superior da carroceria do veículo para evitar que policiais atirassem nos vidros dianteiros. $\mathrm{Na}$ saída da cidade, os bandidos interditaram a PR-160 para evitar a perseguição dos poucos policiais de Curiúva e fugiram, enquanto todos aguardavam o reforço policial (MAROS, 2016). 
Logo, de acordo com Rocha (2012, p. 115), a rota de tráfico internacional existe no Estado do Paraná pelo fato de ele "possuir uma extensa malha rodoviária, que foi construída para o escoamento da produção agrícola". Assim, a autora considera que algumas rodovias se destacam para o escoamento dos grãos e, ao mesmo tempo, para a existência do tráfico de drogas transfronteiriço, como a BR369 e a BR-272, já destacadas. Então, revelam uma contradição, típica do modo de produção capitalista:

O Paraná é um dos estados mais ricos do País, porém, é também um dos estados com pior distribuição de renda. (...) vemos que toda a renda proveniente do agronegócio e da agroindústria, em nada muda a situação real das classes populares, que foram expulsas da zona rural ou vieram para o estado em busca de emprego e melhores condições de vida, e agora vivem em aglomerados urbanos ou zonas rurais com grandes níveis de disparidades sociais (...). Veremos que os adolescentes que foram sujeitos da nossa pesquisa estão em condição de pobreza e só conhecem as rodovias do estado por conta do trabalho prestado como "mula" ao narcotráfico (ROCHA, 2012, p. 144).

Assim, é indispensável abordar a questão dos serviços de segurança pública pela espacialização dos postos policiais, sem desconsiderar a corrupção policial existente, em inúmeros casos, que se vinculam à fronteira e às rodovias paranaenses. Para isso, a Figura 5 apresenta a localização dos postos da Polícia Rodoviária Federal e Polícia Rodoviária Estadual do Paraná no Norte do Estado, em 2015. 
Figura 5. Norte do Paraná. Postos de fiscalização nas rodovias, 2015

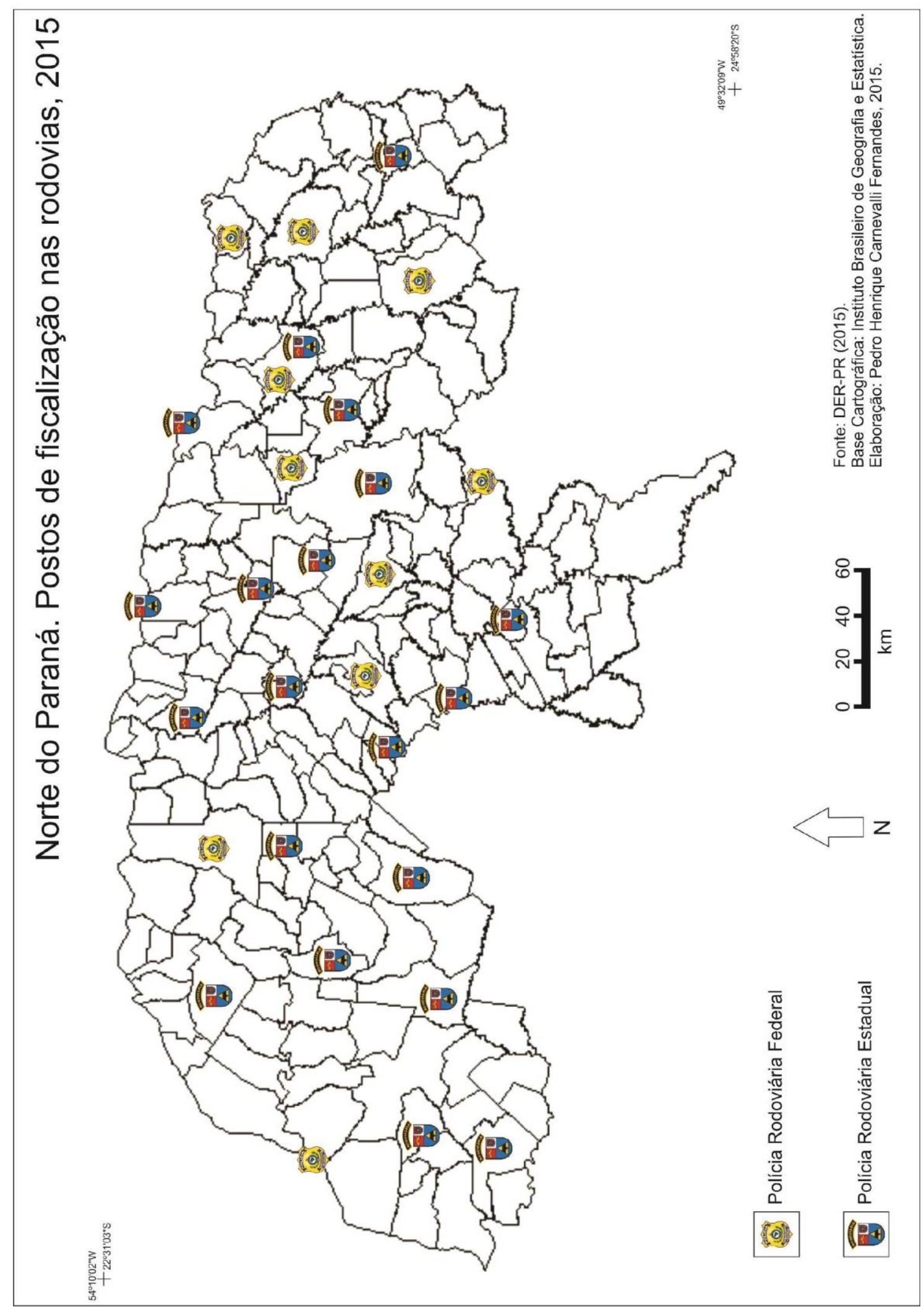

Fonte: Fernandes (2017)

Os dez postos da Polícia Rodoviária Federal estão dispostos na BR-153, em Santo Antônio da Platina e Ibaiti; na BR-369, em Cambará, Cornélio Procópio e Ibiporã; na BR-376, em Paranavaí, Marialva, Apucarana e Mauá da Serra; e na BR- 
487, no pequeno trecho com menos de vinte quilômetros em Icaraíma, na divisa com o Mato Grosso do Sul. Já a Polícia Rodoviária Estadual possui vinte postos de fiscalização, sendo dois na divisa com São Paulo, em Porecatu e Sertaneja, e em diversas rodovias da região, sendo as mais importantes PR-160, PR-090, PR-092, PR-170, PR-323, PR-182.

A partir disso, fica evidente que inúmeros trechos se apresentam como rotas sem fiscalização da segurança pública. No caso das rodovias federais, $50 \%$ dos postos se concentram entre Londrina e o Norte Pioneiro, enquanto os maiores problemas de tráfico estão no lado oposto, na região Noroeste. Além disso, o posto de Paranavaí é responsável por cobrir mais de cem quilômetros de rodovia, enquanto os postos de Ibiporã e de Cornélio Procópio cuidam de menos de sessenta quilômetros. Já as espacializações estaduais deixam a porção Sul do Norte do Estado praticamente abandonada, já que só existe posto em Lidianópolis, e duas rodovias de acesso à São Paulo e ao Mato Grosso do Sul sem postos, PR-542 e PR-317.

Para exemplificar essas reflexões, foram elaboradas duas rotas, saindo de Guaíra, cidade fronteiriça com o Paraguai, passando apenas por cidades do Norte do Estado do Paraná até chegar ao Estado de São Paulo, sem passar por nenhum posto de fiscalização das polícias federal e estadual. Contudo, optou-se por omitir os caminhos para não configurar uma cooperação com a violência e a insegurança objetiva que se associam ao tráfico e seus desdobramentos. O primeiro trajeto passou por 23 municípios, sendo 18 pequenas cidades, 376 quilômetros e 15 rodovias diferentes. Na segunda rota, percorreram-se 31 municípios, sendo 23 pequenas cidades, 556 quilômetros e 22 rodovias diferentes. Além disso, de Itaguajé ainda seria possível seguir até Maringá, por mais 130 quilômetros, Londrina, a 150 quilômetros, ou Cornélio Procópio, a 190 quilômetros, sem passar por nenhum posto de fiscalização das polícias rodoviárias estadual e federal.

O debate sobre a fronteira é complexo e não pode ser olvidado pela universidade. Por isso, tentou-se transitar por explicações teóricas e empíricas, desde a fronteira e a faixa de fronteira, a articulação delas com a rede internacional de tráfico, mostrando a situação preocupante de tráfico de pessoas, até as rodovias, como lócus do escoamento dos crimes de fronteiras. É fundamental pontuar que, embora as explicações sejam gerais, focaram-se as pequenas cidades em diversos momentos para mostrar que elas não fogem do contexto. 


\section{Considerações Finais}

Efetivamente, compreender, em totalidade, o espaço geográfico a partir da realidade humana foi uma das tarefas mais complexas deste artigo. Isso se deve pela multiplicidade de olhares e leituras do espaço. Além disso, a complexidade se potencializa pelo tema, que envolve abordar a violência e a insegurança objetiva, e pelo recorte, que se volta para as pequenas cidades, seja para o pesquisador, que transita por espaços com altas taxas de homicídios, seja para os respondentes da comunidade local, que discursam sobre um tema causador de insegurança em espaços marcados pela pessoalização.

A violência e a insegurança objetiva em pequenas cidades se justificam, em parte, pela dinâmica do tráfico ilícito, principalmente de pessoas, drogas e produtos contrabandeados, além de outras ramificações, como corrupção, sonegação fiscal, lavagem de dinheiro, evasão de divisas, exploração sexual etc. As áreas fronteiriças são espaços marcados e reconhecidos pela existência de uma violência quase que crônica. É comum encontrar trabalhos acadêmicos, políticas públicas e programas sociais, como o Enafron e o Narcondenúncia; e reportagens dos meios de comunicação sobre a violência em diversas pequenas cidades.

A ausência ou a insuficiência do Estado nas fronteiras e faixas de fronteiras por uma perspectiva mais social e humana e menos pela de controle e de zonas militares, impulsionou o desenvolvimento de atividades ilegais que influenciam na violência e na insegurança objetiva. Assim, existem duas abordagens, indissociáveis, sobre isso. Na primeira, em escala global, a violência e insegurança se vinculam ao processo de globalização da criminalidade organizada a partir do fenômeno social que permitiu a transnacionalização das atividades ilegais em nível global. No caso do narcotráfico, ele é composto por estruturas organizadas, com ampla divisão do trabalho, como nas empresas "legais". Na segunda abordagem, em escala local, a violência e a insegurança objetiva nas fronteiras e nas faixas de fronteira decorrem de contextos e situações locais e regionais.

Apesar da multiplicidade de motivações para a violência e para a insegurança objetiva nas cidades de fronteira e de faixa de fronteira, a que tem maior relevância, inclusive na economia e na política mundial de controle do território (produção de territorialidades), é o tráfico de drogas ilícitas e de produtos contrabandeados. Nesse sentido, tem-se a territorialização desses espaços pela multiplicidade de poderes, particularmente na dualidade forças militares do Estado versus narcotraficantes. 
O Narcodenúncia, do Governo do Estado do Paraná, demonstrou que várias pequenas cidades do Norte do Paraná possuíam altas taxas de presos e apreendidos por tráfico de drogas, como Assaí, Cruzeiro do Oeste, Iguaraçu, Inajá, Jataizinho, Maria Helena e Perobal. Iporã também se destacou nesse sentido. $O$ outro lado revelado pela $\mathrm{CPI}$ do Narcotráfico mostrou o envolvimento de maneira cristalizada de agentes estatais de segurança pública do Paraná, como superintendentes, delegados e investigadores, no narcotráfico.

O debate sobre a fronteira é complexo e não pode ser olvidado pela universidade. Por isso, tentou-se transitar por explicações teóricas e empíricas, desde a fronteira e a faixa de fronteira, a articulação delas com a rede internacional de tráfico, mostrando a situação preocupante de tráfico de pessoas, até as rodovias como lócus do escoamento dos crimes de fronteiras. Portanto, é fundamental pontuar que, embora as explicações sejam gerais, focaram-se as pequenas cidades em diversos momentos para mostrar que elas não fogem ao contexto.

\section{REFERÊNCIAS}

ARANGO, Azucena. La sensación de inseguridad: calles cerradas en Conjuntos Habitacionales periurbanos de la Ciudad de México. Scripta Nova: Revista Eletrónica de Geografia y Ciencias sociales, vol. XVIII, № 493(54), 2014, p. 1-16.

BELO, Carolina Gabardo. Falta de policiais deixa rodovias estaduais à mercê dos marginais. 04/11/2015. Portal Paraná Tribuna, 2015. Disponível em:

<http://www.tribunapr.com.br/noticias/parana/falta-de-policiais-deixa-rodovias-estaduais-amerce-dos-marginais> acesso em: 1 fev. de 2016.

BEZERRA JÚNIOR, Benilton. Pobreza, agressividade e consumo: três observações sobre a violência no Brasil. FEGHALI, Jandira; MENDES, Candido; LEMGRUBER, Julita (Orgs.).

Reflexões sobre a violência urbana: (In)segurança e (Des)esperanças. Rio de Janeiro: Mauad X, 2006, p. 43-59.

BRASIL, Casa Civil. Lei no 6.634 de 02/05/1979: que dispõe sobre a Faixa de Fronteira. 1979.

BRASIL, Ministério da Integração Nacional. Faixa de Fronteira: Programa de Promoção do Desenvolvimento da Faixa de Fronteira - PDFF. Brasília: 2009.

BRASIL, Ministério da Integração Nacional. Proposta de reestruturação do Programa de Desenvolvimento da Faixa de Fronteira: base de uma política integrada de desenvolvimento regional para a faixa de fronteira. Brasília: Ministério da Integração Nacional, 2005.

DER-PR, Departamento de Estradas de Rodagem do Paraná. Rodovias do Paraná. 2015. Disponível em: <http://www.der.pr.gov.br/> acesso em: 30 dez. de 2015. 
DORFMAN, Adriana. Contrabandistas na fronteira gaúcha: escalas geográficas e representações textuais. Tese (doutorado) - Universidade Federal de Santa Catarina, Programa de Pós-graduação em Geografia, 2009.

FERNANDES, Pedro Henrique Carnevalli Fernandes. Um espectro ronda as pequenas cidades: o aumento da violência e da insegurança objetiva. 525 p. Tese (doutorado). Programa de Pós-Graduação em Geografia da Universidade Estadual de Maringá. Maringá, 2017.

HAESBAERT, Rogério. Território e multiterritorialidade: um debate. GEOgraphia, v. 9, no 17, p.19-46, 2007.

IBGE. Instituto Brasileiro de Geografia e Estatística. Censo Demográfico. 2010. Disponível em: <http://www.censo2010.ibge.gov.br/resultados_do_censo2010.php> acesso em: 3 mar. de 2015.

MACHADO, Lia Osório. A estratégia nacional de defesa, a Geografia do tráfico de drogas ilícitas e a Bacia Amazônica Sul-Americana. Seminário de Defesa e Desenvolvimento Sustentável da Amazônia. Rio de Janeiro: Escola de Comando e Estado-Maior do Exército, 2010, p. 99-113.

MACHADO, Lia Osório. Limites e fronteiras: da alta diplomacia aos circuitos da ilegalidade. Território, Rio de Janeiro, ano V, no 8, p. 9-29, 2000.

MAROS, Angieli. Quadrilha faz reféns antes e depois de assalto a banco em Curiúva. 19/01/2016. Gazeta do Povo, 2016. Disponível em: <http://www.gazetadopovo.com.br/vidae-cidadania/quadrilha-faz-refens-antes-e-depois-de-assalto-a-banco-em-curiuva $>$ acesso em: 1 fev. de 2016.

MISSE, Michel. A violência como sujeito difuso. FEGHALI, Jandira; MENDES, Candido; LEMGRUBER, Julita (Orgs.). Reflexões sobre a violência urbana: (In)segurança e (Des)esperanças. Rio de Janeiro: Mauad X, 2006, p. 19-31.

PARANÁ, Governo do. Secretaria da Segurança e Administração Penitenciária. Estatística: homicídios e apreensão de drogas. 2015. Disponível em:

$<$ http://www.seguranca.pr.gov.br/modules/conteudo/conteudo.php?conteudo=38> acesso em: 22 mar. de 2015.

PARANÁ, Governo do. 181 Narcodenúncia: Mapeamento dos resultados contra o narcotráfico realizado pelas polícias Militar, Civil, Federal e Rodoviária Federal. 2016. Disponível em: <http://www3.pr.gov.br/narcodenuncia/relatorios/rel_atendmunic.php?opt=4> acesso em: 27 jan. de 2016.

PCPR, Polícia Civil do Estado do Paraná. A “Rota Caipira do tráfico”. 2010. Disponível em: <http://www.policiacivil.pr.gov.br/modules/noticias/article.php?storyid =2872> acesso em: 1 fev. de 2016 .

PORTAL DA CIDADE. Com apreensões diárias, PR-323 é uma das rotas mais usadas pelo crime. 04/08/2015. 2015. Disponível em:

<http://umuarama.portaldacidade.com/noticia/22403-com-apreensoes-diarias-pr-323-e-umadas-rotas-mais-usadas-pelo-crime> acesso em: 1 fev. de 2016.

PORTAL G1/PR, Norte e Noroeste. Polícia Rodoviária Federal acha carreta cheia de maconha e faz maior apreensão de 2015 no país. 23/11/2015. 2015. Disponível em: <http://g1.globo.com/pr/norte-noroeste/noticia/2015/11/prf-faz-maior-apreensao-de-drogasde-2015-em-icaraima-no-parana.html> acesso em: 1 fev. de 2016. 
RIBEIRO, Diego; RIEGER, Thomas. Conta atrasada gera corte nos telefones da PM e da SESP. 20/11/2013. Gazeta do Povo, 2013. Disponível em:

<http://www.gazetadopovo.com.br/vida-e-cidadania/conta-atrasada-gera-corte-nos-

telefones-da-pm-e-da-sesp> acesso em: 9 dez. de 2015.

ROCHA, Andréa Pires. Trajetórias de adolescentes apreendidos como "mulas" do transporte de drogas na região da fronteira (Paraná) Brasil - Paraguai: exploração de força de trabalho e criminalização da pobreza. $396 \mathrm{f}$. Tese (Doutorado em Serviço Social). Universidade Estadual Paulista, Franca, 2012.

ROCHA, Marcelo. Estradas no Paraná têm um roubo de carga a cada dois dias, diz sindicato. 22/03/2013. Portal Bom Dia Brasil, 2013. Disponível em:

<http://g1.globo.com/bom-dia-brasil/noticia/2013/03/estradas-no-parana-tem-um-roubo-decarga-cada-dois-dias-diz-sindicato.html> acesso em: 1 fev. de 2016.

TEIXEIRA, Maria Cecília Sanches; PORTO, Maria do Rosário Silveira. Violência, insegurança e imaginário do medo. Caderno Cedes, Campinas, v. 19, n. 47, p. 51-66, dez., 1998.

\section{NOTAS DE AUTOR}

\section{CONTRIBUIÇÃO DE AUTORIA}

Pedro Henrique Carnevalli Fernandes - Concepção. Conceituação. Coleta de dados. Análise de dados. Investigação. Metodologia. Elaboração do manuscrito, revisão e aprovação da versão final do trabalho. Angela Maria Endlich - Concepção e elaboração do manuscrito. Participação ativa da discussão dos resultados. Supervisão. Validação. Revisão e aprovação da versão final do trabalho.

\section{FINANCIAMENTO}

Não se aplica.

\section{CONSENTIMENTO DE USO DE IMAGEM}

Não se aplica.

\section{APROVAÇÃO DE COMITÊ DE ÉTICA EM PESQUISA}

Não se aplica.

\section{CONFLITO DE INTERESSES}

Não há conflito de interesse.

\section{LICENÇA DE USO}

Este artigo está licenciado sob a Licença Creative Commons CC-BY. Com essa licença você pode compartilhar, adaptar, criar para qualquer fim, desde que atribua a autoria da obra.

\section{HISTÓRICO}

Recebido em: 10/04/2020

Aprovado em: 15/07/2020 